\title{
Awareness of risks related to oral piercing in Italian piercers. Pilot study in Lazio Region
}

\author{
Iole Vozza, DDS, PhD \\ Francesca Fusco, BSDH \\ Ercole Bove, MD, DDS \\ Francesca Ripari, DDS \\ Denise Corridore, DDS \\ Livia Ottolenghi, DDS
}

Oral and Maxillo-facial Sciences Department, "Sapienza" University of Rome, Italy

\author{
Corresponding author: \\ lole Vozza DDS, PhD \\ Oral and Maxillo-facial Sciences Department \\ "Sapienza" University of Rome \\ Via Caserta, 6 \\ 00161 Rome, Italy \\ Phone: +390649976612 \\ Fax: +390644230811 \\ E-mail:iole.vozza@uniroma1.it
}

\section{Summary}

Objective. Specific regulations about education and training for body piercing licensure courses have to be considered due to the great increase in oral piercing practices. The aim of the present survey was to assess the local and systemic risk awareness in the practice of oral piercing and their prevention in a sample of Italian piercers.

Materials and methods. An anonymous 20-item questionnaire was administered to 30 body licensed piercers in a small town of central Italy. Licenses certificates were issued by Lazio Region after the completion of an approved training program for standard body piercing including 90 hours of course and a final examination as provided by regional law. The questionnaire surveyed on oral cavity anatomy, local and systemic risks as result of oral piercing, piercing maintenance and need of a dental visit.

Results. Response rate was $66.6 \%$. Only $20 \%$ of respondents was aware about oral cavity anatomy and none had knowledge about tongue and gums anatomy. Only $10 \%$ enlightened the need of a dental visit and $30 \%$ was aware about piercingrelated temporary paralysis. The piercing maintenance was habitually proposed only by $40 \%$ of respondents.

Conclusion. The study participants showed a low level of awareness regarding the potential health risks of oral piercing. Poor knowledge of anatomy and local and systemic risks and poor awareness of the importance of piercing maintenance explanation.

Key words: oral piercing, oral health, oral complications.

\section{Introduction}

The practice of piercing has ancient origins. The main purpose was to distinguish the roles played by each member within the tribe, in order to regulate the relationship between the various individuals daily and during ceremonies (1). Over the past two decades body piercing exceed from the limits of the typically underground environment to become common practice among youngsters and artists. Its recent spread among young people rise the issue of potential health complications (2). The international guidelines pay attention especially on security measures and jewelry materials, but there are no directions on piercing in terms of hygiene and maintenance (3), even though in some country cardiopulmonary resuscitation, basic first aid and blood borne pathogens trainings from an agency-approved provider is required.

Oral piercing can be applied in different anatomical areas: lips, tongue, cheeks, uvula, lingual and labial frenulum in decreasing percentage (4).

Complications of oral piercings have been discussed in literature and include local and general complication, with potentially severe health consequences. These include cross-infection (HIV, HCV, HAV, HBV and HSV), bacterial and viral problems (endocarditis, Focal Disease, Gingivitis, Lingual abscess), short and long-term local issues related to piercings (ageusia, hypogeusia, gingival recession, diastema, chipping or dental fracture and scialorrhea) and allergic reactions to the jewelry materials $(2,5-8)$.

As trend of body piercing grow in popularity, understanding the procedures'risks as well as medical and psychosocial implications of wearing piercing jewelry is important for health practitioners. It would be advisable for sanitary authorities to establish regulating legislation for body piercing license. Some countries have already laid down different standards and technical criteria, which in certain cases have been appended to the legislation applied to hairdressers' shops and beauty salons, as well as to security measures applied in multiple fields to prevent the transmission of infectious diseases. However, in 
other cases, specific regulations have been considered. European Standard UNI EN 18.10 on $10^{\text {th }}$ September 2002 focuses purely on sanitation standards of sterilization and disinfection and on trade regulations.

In Italy, despite the strong expansion of the tattoo and piercing phenomenon, there is no methodical regulation of the matter. The only relevant national legislation dates back to 1998 and is represented by the "Guidelines issued by the Ministry of Health for the execution of tattoos and piercings in safety". (Notes N. 2.8/156 of 5 February 1998 and n.2.8/633 of 16 July 1998). The objective of these guidelines is to prevent improvised operators or malpractice (9). In fact, although the tattoo and piercing are not medical practices, their execution is extremely delicate and requires appropriate safeguards in hygiene standards (10). Requirements for licensees, education and training of piercers, number of hours to attend and topics to be discussed during the course, are taken by the Region of residence. This leads to a not uniform preparation of piercers/tattooists throughout the country. In Lazio Region the training is based on 90 hours of course (Regional Law 4796/1998) while, for example, in Tuscan Region the hours to attend are 600 (Regional Law 28/2004).

The goal of this work is to assess the awareness of risks in the practice of oral piercing and their prevention in a sample of Lazio Region-based piercers.

\section{Materials and methods}

In September 2013 an anonymous 20-item survey was administered to 30 body piercers (both sexes, aged between 27 and 42 years old) living and working in the Province of Latina, Lazio Region. The questionnaire collected data on oral cavity anatomy, local and systemic risks as result of oral piercing and piercing maintenance. All piercers were licensed by a certificated Lazio Region training course, that includes the attendance of 90 hours and a final examination, as provided by regional law. Each piercer answered the questions at his own office and the considered variables were:

- knowledge of the anatomy of oral cavity, tongue and gingivae;

- knowledge of the methods of sterilization and blood-borne infections (HIV, HCV and HBV);

- details on local piercing-related risks such as: ageusia, hypogeusia, endocarditis, allergic reactions to the materials used, lingual abscesses, gum disease, gingival recession, tooth chipping or fracture, diastema and hypersalivation;

- details on piercing maintenance through mouthwashes rinses, antiseptic gels or creams, brushing of piercing bar and need of a dental visit.

At the end of the survey we distributed to all participants an explanatory brochure containing a brief description of the potential complications, modes of piercing maintenance and the advice for a dental visit at least once after piercing.

\section{Results}

Twenty out of the 30 involved licensed piercers answered the survey, with a response rate of $66.6 \%$.

The results of this survey are summarized in Figures 1 and 2.

\section{Anatomical knowledge}

Only 4 out of 20 respondents (20\%) showed awareness of oral anatomy, while the remaining $16 \mathrm{de}$ clared they had not discussed the issue during the training course. All the respondents (100\%) were unaware of tongue and gums anatomy, the topic having not been addressed during the training course.

\section{Piercing-related risks, maintenance and dental visit}

Only 6 out of 20 (30\%) declared to habitually explain to their customer spiercing-related risks and maintenance instructions. Methods of maintenance such as

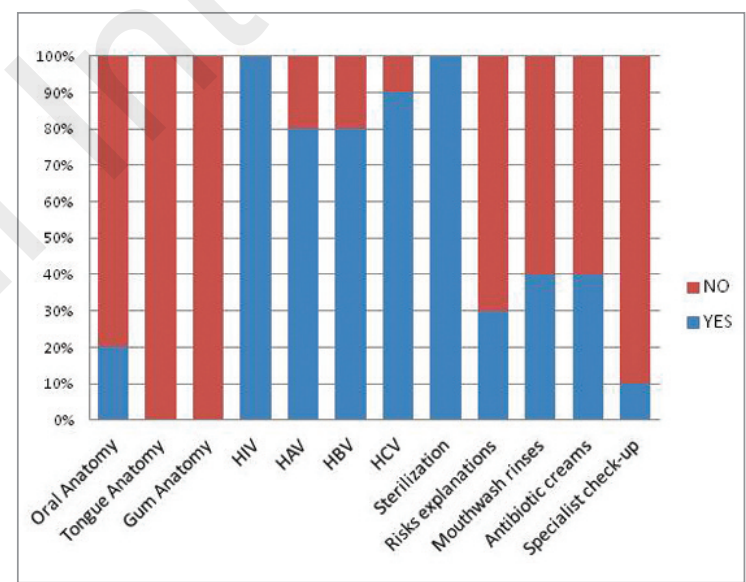

Figure 1. Knowledge of anatomy, risks and maintenance of oral piercing among operators.

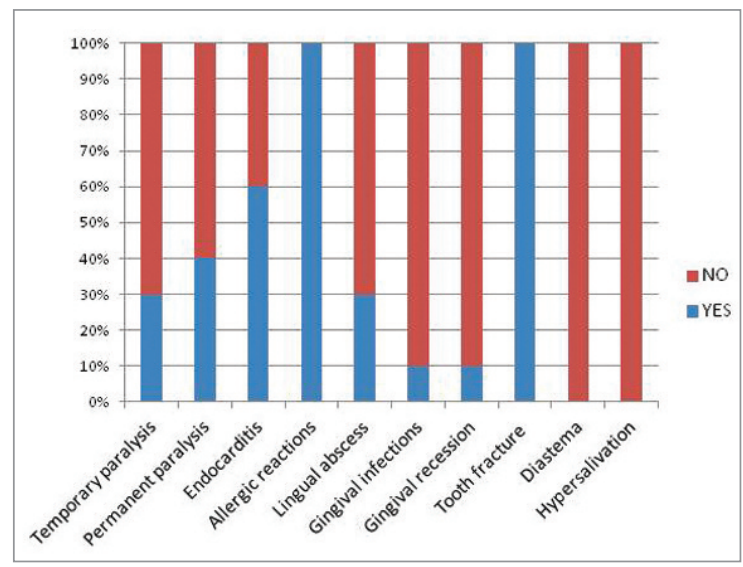

Figure 2. Knowledge of systemic risks related to piercing among operators. 
mouthwash rinses, antiseptic gels and creams and piercing barbrushing, were explained by 8 out of 20 operators (40\%), whereas the remaining 12 habitually omitted this step (60\%).

Dental visit was recommended by 2 respondents $(10 \%)$ while the remaining $18(90 \%)$ stated they had never thought about recommending a dental visit.

\section{Systemic and local risks related to piercing}

With regard to blood borne viral infection, knowledge and understanding (11) was encouraging: the whole sample $(100 \%)$ declared they had dealt extensively disinfection and sterilization methods and HIV crossinfections during the training course, $90 \%$ (18 out of 20) reported to be aware of $\mathrm{HCV}$ infection risk and $80 \%$ (16 out of 20 ) claimed to be aware of HAV and HBV infection risk.

Only $60 \%$ (12 out of 20 ) was aware about risks of endocarditis. Only 6 operators were aware about risk of temporary paralysis (30\%) and 8 operators (40\%) about permanent paralysis.

Only 6 out of $20(30 \%)$ were aware about lingual abscess risks, while only 2 of $20(10 \%)$ reported knowledge on the risk of gingival infection and recession. All respondents $(100 \%)$ showed awareness of the risk of allergic reactions to the jewelry materials. About tooth chipping or fracture all respondents were aware, while none of the respondents expressed awareness about risk of diastema or hypersalivation.

\section{Discussion and Conclusion}

Considering the continuous increase in the youth population of piercings and tattoos, it is important that awareness of health risks associated with this practice is supported with adequate training and information to all people involved (i.e. operators and users) (12). As mentioned above, the license training for professional piercers is different in each Italian Region and the content of the course is not always appropriate. In this study emerges that not all the topics included in the training course program have been properly addressed, since the surveyed licensed piercers were almost completely unaware of oral anatomy. The provided hours of course (overall 90 hours including classroom teaching and practice) appear to be inadequate to meet the expected professional requirements skills and knowledge. The piercers indeed resulted uninformed on issues that should be part of their professional background. The unawareness of operators about the potential complications of piercing on health constitutes a further health risk factor for users.

Piercers should therefore be appropriately trained in order to be acquainted with the potential harm caused by their work mismanagement (13). The ne- cessity that emerges from the results of the present pilot survey is to operate in order to improve the health-related contents of tattoo artists and piercers course, and to increase information regarding these issues in schools among youngsters. Due to its potential risks it is important for oral health care professionals to become familiar with the characteristics of each type of piercing in order to act accordingly (14). How can users be aware of piercing-related health issues if the operators themselves are unaware? Further research in this area is necessary. The sustainability of the collected data needs to be established in further studies with a greater samples.

\section{References}

1. Choe J, Almas K, Schoor R. Tongue piercing as risk factor to periodontal health. N Y State Dent J. 2005 AugSep;71(5):40-3.

2. Singh A, Tuli A. Oral piercings and their dental implications: a mini review. J Investig Clin Dent. 2012 May;3(2):95-7.

3. Randall JA, Sheffield D. Just a personal thing? A qualitative account of health behaviours and values associated with body piercing. Perspect Public Health. 2013 Mar;133(2):110-5.

4. Hennequin-Hoenderdos NL, Slot DE, Van der Weijden GA. Complications of oral and peri-oral piercings: a summary of case reports. Int J Dent Hyg. 2011 May;9(2):101-9.

5. Ziebolz D, Hornecker E, Mausberg RF. Microbiological findings at tongue piercing sites: implications to oral health. Int J Dent Hyg. 2009 Nov;7(4):256-62.

6. Oberholzer TG, George R. Awareness of complications of oral piercing in a group of adolescents and young South African adults. Oral Surg Oral Med Oral Pathol Oral Radiol Endod. 2010 Dec;110(6):744-7.

7. Tabbaa S, Guigova I, Preston CB. Midline diastema caused by tongue piercing. J Clin Orthod. 2010;44:426-8.

8. Plessas A, Pepelassi E. Dental and periodontal complications of lip and tongue piercing: prevalence and influencing factors. Aust Dent J. 2012 Mar;57(1):71-8.

9. Mansi A, Vonesch N, Tini MN, Di Mambro A, Cianotti R, Palmi S, Spagnoli G.Semi-permanent make up and tattooing equipment: safety and health issues. Ig Sanita Pubbl. 2004 Nov-Dec;60(6):437-57.

10. Stein T, Jordan JD. Health considerations for oral piercing and the policies that influence them. Tex Dent J. 2012 Jul;129(7):687-93.

11. Ministry of Science, Technology and Innovation. A Framework for Qualifications of the European Higher Education Area. Bologna Working Group on Qualifications Frameworks. 2005;57-74.

12. Palacios-Sánchez B, Cerero-Lapiedra R, Campo-Trapero J, Esparza-Gómez G. Oral piercing: dental considerations and the legal situation in Spain. Int Dent J. 2007 Apr;57(2):60-4.

13. Oberdorfer A, Wiggers JH, Bowman J, Burrows S, Cockburn $\mathrm{J}$, Considine RJ. Monitoring and educational feedback to improve the compliance of tattooists and body piercers with infection control standards: a randomized controlled trial. Am J Infect Control. 2004 May;32(3):147-54.

14. Vieira EP, Ribeiro AL, Pinheiro Jde J, Alves S de M Jr. Oral piercings: immediate and late complications. J Oral Maxillofac Surg. 2011 Dec;69(12):3032-7. 